\title{
Study on Linkage Development of Revitalization of the Old Industrial Base in Northeast China and Exploitation of Russian Far East Area
}

\author{
Huiling Yu \\ College of Economics and Management, Heihe University, Heihe, Heilongjiang, 164300, China
}

Keywords: The old industrial base in northeast China, Russia, Development of Far East area, Linkage countermeasures.

\begin{abstract}
To further facilitate the revitalization and development of the old industrial base in northeast China, it is required to adequately establish effective connection with the economic development in Russian Far East Area to form a linkage effect and realize complementary advantages for both sides. At present, according to the specific analysis on situation, there are many problems in the cooperation between the old industrial base in northeast China and the Russian Far East Area. Therefore, this paper puts forward corresponding countermeasures through analysis on restriction factors of linkage of both sides in the hope of facilitating the new revitalization of the old industrial base in northeast China and the development of Russian Far East Area to enter into the road of linkage development.
\end{abstract}

\section{Introduction}

In a broad sense, linkage specifically means several correlated things. Any movement or dynamic change in one of them will result in a specific movement or change in other things. The construction and development of old industrial base in northeast China and extremely closely related to the exploitation of Russian Far East Area; there is even a long-term special correlation in economic growths, cultural exchanges, technological innovations and industrial development between the two areas. Their development goals have the regional similarity so they can cause corresponding linkage effect in the process of construction. Therefore, during practical construction, they both can take some measures to promote linkage development of the two areas, realize complementary advantages in economic and cultural construction within corresponding regions and thus obtain the huge achievements in regional coordination and development. For this reason, it is of an extremely realistic significance to analyze the factors and development countermeasures for linkage development of Russian Far East Area and the old industrial base in northeast China at the present stage.

\section{Analysis on influencing factors of linkage development of revitalization of the old industrial base in northeast China and exploitation of Russian Far East Area}

\section{Influence of the theory of China threat}

As shown in relevant investigations, with the development of northeast China and the continuously deepening cooperation between northeast China and Russia Far East Area in economic and cultural construction, the northeast China's gross export to Russia accounts for a growing percentage in China and even reaches up to over 30\%, so northeast China has become a hub for foreign trade activities in China. Besides, the development and construction department of Russia Far East Area also realized that it is required to strengthen the connection with northeast China to achieve success in the development and construction of Russia Far East Area and that better economic and cultural 
development can be obtained in both areas through both sides' linkage. However, there are certain historic characteristics and particularity in Sino-Russian relationship; Chinese immigrants and other problems always affect their thoughts; the "theory of China threat" has a significantly restrictive effect on both sides' economic and trade cooperation ${ }^{[1]}$. According to the investigations made by departments concerned, the majority of Russians in Far East Area feels insecure and disturbed for Chinese immigrants and thinks that extremely strict limitations are required. Since the end of last century, the Russian media has always been propagandizing a theory of China threat in the official propaganda process, going against the linkage development between the old industrial base in northeast China and Russian Far East Area.

\section{Lack of corresponding system guarantee in cooperation between both sides}

In the past few years, China attaches more importance to the cooperation with Russia, actively established strategic partnership and actively deepened the development of economic and trade relationship between China and Russia. In addition, based on Sino-Russian cooperation, the heads of the two countries also signed corresponding cooperative agreements, which caused certain positive influences on the continuous and stable growth in the bilateral trade between China and Russia. However, the deepening and development of Sino-Russia trade cooperation still lack system guarantee regardless of such mutually cooperative relationships, policies and guidelines. Firstly, there is a lack of legal support in the implementation of economic and trade cooperation activities between northeast China and Russian Far East Area. Currently, the economic and trade cooperation between northeast China and Russian Far East Area is executed mainly under the codes of the WTO's relevant regulations and lacks the guarantee of compulsory laws and regulations; this goes against the deep development of economic and trade cooperation. Secondly, there is no long-acting cooperative mechanism in the economic and trade cooperation between northeast China and Russian Far East Area. Some cooperative disputes caused due to non-standardized cooperative agreements during Sino-Russia economic and trade cooperation has corresponding adverse influences on the construction of a long-acting cooperative mechanism. Finally, there are some other barriers such as officials' corruption and cooperative cognition in coordination and implementation of all work in the field of economic and trade cooperation between both sides, causing adverse influences on positive cooperation.

\section{Economic factors}

As neighboring countries, China and Russia have strong economic complementarity and their geographic advantages are relatively obvious. The two countries' amount of economic and trade cooperation has been increasing continuously since the end of last century and broke through the 80 billion mark in the first decade of this century. China once became the Russia's greatest bilateral trade partner and Russia is also one of China's most crucial economic and trade cooperation countries. The two countries have made great achievements in energy, electromechanics, forestry, aviation, agriculture, light industry and many other fields during their mutual cooperation. However, there is still a wide difference between such achievements attained and the cooperative potential between both countries. As a key area for China's trade to Russia, the northeast China also made relatively limited achievements in trade with Russia ${ }^{[2]}$. Firstly, the cooperation between China and Russia Far East Area mainly focuses on trade for a long time and the deep cooperation in production and investment is insufficient; secondly, it is difficult to carry out deep cooperation because the economic and trade cooperation between northeast China and Russia Far East Area mainly is dominated by product trade with low additional value and followed by relatively fewer products with high values; thirdly, subjective and objective barriers in cooperation between northeast China and Russia Far East Area in economy, energy, infrastructure and other new fields also have negative influences on the improvement of cooperative quality; finally, the relatively backward infrastructure in bilateral trade resulted in a certain bottleneck in Sino-Russia cooperation and cannot meet the development requirements of clearance in practical development process. 


\section{Cultural factors}

Economic and trade cooperation can facilitate both countries' cultural exchanges and development while cultural exchanges and development will certainly exert a positive influence on both countries' economic and trade cooperation. In recent years, although some achievements have been made in cultural exchanges between northeast China and Russia Far East Area, there are still some problems from the overall development trend in essence. Firstly, the cultural exchanges between northeast China and Russia Far East Area still remain the practical level instead of form a systematic theory so they cannot have great influences on the deep development of economic and trade cooperation; secondly, Russian culture absorbed and introduced by northeast China involves relatively wide fields is developed in an unbalanced way, fails to cause cultural economy effect and thus cannot drive the economic and trade cooperation between northeast China and Russia Far East Area attain prosperity. Thirdly, there is a striking contrast between the pervasiveness and profundity of governments' cultural exchanges and the scarcity of people's cultural exchanges. The northeast China and Russia Far East Area have organized many cultural exchange and cooperation activities with various forms and abundant contents at the governmental level, which drove the economic prosperity and development of both areas to some degree and have positive influences on the friendship between the two countries. However, such cultural exchanges are limited to governments, fail to largely affect people's production and life and don't cause significant influences on Sino-Russia economic and trade cooperation ${ }^{[3]}$. Finally, there are no perfect legal and regulation guarantees in the economic and trade cooperation between both sides. Although both countries have entered WTO and trade disputes between both sides can be solved as per WTO's relevant provisions, such provisions, which are merely general provisions, cannot completely solve such disputes because the trade cooperation between two bilateral trade entities has its own characteristics. For this reason, Heilongjiang and Russia Far East Area need to sign some legal documents about local economic and trade cooperation to guarantee their economic benefits and actively promote the growths in both sides' trade volumes.

\section{Feasibility analysis on linkage of revitalization of the old industrial base in northeast China and exploitation of Russian Far East Area}

\section{Policy}

The economic development strategies of both countries provide an uncommon policy opportunity for linkage of both sides. Chinese government's corresponding guidance regarding the revitalization of the old industrial base in northeast China issued at the beginning of this century marked that the strategy of revitalizing the old industrial base in northeast China was officially launched and operated, and exerted extremely important influences on the economic development in northeast China. After the policy about the old industrial base in northeast China was implemented and carried out accordingly, China's departments concerned took corresponding preferential policies and measures in practical work including perfecting the modern industry system, enhancing the comprehensive development ability of the city, stimulating new advantages of industrial competition, reinforcing innovative support ability etc. in the hope of achieving deep implementation of the strategy of revitalizing the old industrial base in northeast China ${ }^{[4]}$. In the past few years, China and Russia paid more attention to the development of northeast China and Russia Far East Area, jointly approved the Planning Outline of Cooperation between Northeast China and Russian Far East Area and East Siberian Area (hereinafter referred to as Planning Outline), where concrete cooperative planning was made for cooperation and exchange between northeast China and Far East Area of both countries. Thus, it can be seen that the Planning Outline created a corresponding policy opportunity for linkage development of both areas.

\section{Geographic relationship}


Regional advantages facilitate the economic linkage development of both areas. Spatial and geological differences have trade cost attribute. To put it simply, it means all the costs including customs duties, quota, transportation, warehousing, sales and insurance etc. incurred by conveying the final consumption products to consumers in economic activities. Such economic costs still exist in economic and trade communications among countries and have extremely significant influences on the economic development of various regions. In specific economic and trade activities, trade costs are affected by degree, distance and other factors. The obvious geographic advantages of northeast China and Russian Far East Area, short transportation distance and convenient air-sea-land stereo-traffic network largely reduce the trade costs and show prominent comparative advantages, so they all will certainly promote the revitalization of the old industrial base in northeast China and the exploitation of Russia Far East Area.

\section{International situation}

As the global financial crisis resulted in severe economic recession for western countries, the global key point is gradually changed into Asian-Pacific region. The strategy of "returning to Asia-Pacific region" put forward by America inevitably aroused the great concern of China and Russia, two core great powers in Asian-Pacific region. To curb the global strategy of world supremacy, it is the inevitable choice to reinforce the linkage development of revitalization of the northeast China and exploitation of Russia Far East Area for world multipolarization and peaceful development. Russia's cooperation with China and its further exploitation of Far East Area, Transbaikalia and East Siberian area are of highly principled significance for Russia's implementation of economic strategies, realization of economic modernization, development of innovative economic and integration into Asia-Pacific Region.

\section{Countermeasures and suggestions on linkage of revitalization of the old industrial base in northeast China and exploitation of Russian Far East Area}

Firstly, quicken the construction of economic corridor among China, Mongolia and Russia and build the great channel for linkage development. Through cooperation regarding railway, highway, port and airport construction, strengthen the construction of port infrastructure, enhance clearance ability and efficiency, actively promote the construction of free trade zones in ports along the line, propel the facilitation progress of international trade, international logistic liberalization and international investment, form complementation of resource advantages and create industrial cluster districts in the opening-up belts along the border.

Secondly, create a great market for linkage development in virtue of the Sino-Russia cross-border electronic commerce platform. The economic crisis and western sanctions resulted in continuous economic deterioration of Russia and people's increasingly low consumption ability, so the convenient and swift shopping with price advantages has won the acceptance of a growing number of people. Even though such a consumption form just started to be popular in Moscow and other developed areas, Russian Far East Area more needs such an electronic commerce platform service based on the economic situation and traffic condition in this area regardless of its enterprise production, individual life, consumption demand and commodity sales. Import and export trades through such a cross-border electronic commerce platform can rapidly diffuse corresponding trade information, enhance trade efficiency and benefits, and simultaneously construct a great market for linkage development of both areas.

Thirdly, stimulate the innovative potential of linkage development in virtue of educational cooperation. Colleges and relevant research organizations play important roles in facilitating the development of economy and society within the same construction development region. When college students or related teaching \& research institutes have certain relations with industrial construction, they can smoothly convert knowledge into a rather advanced productive force to propel the rapid development of economy and society. There has always been a corresponding cooperative and mutually beneficial relationship between the revitalization of the old industrial base in northeast 
China and the exploitation of Russian Far East Area. Based on this relationship, strengthening educational cooperation between both sides can stimulate the linkage of economic and trade cooperation. The educational cooperation between northeast China and the exploitation of Russian Far East Area can cause the two effects below. The first is spatial centralization effect of knowledge. Since the externality of knowledge is usually restrained and affected by space, there must be corresponding correlation between innovations in education of both areas from the spatial level. During the development of northeast China and Russia Far East Area, China and Russia can take corresponding measures for educational cooperation based on the geological neighboring advantages to promote knowledge centralization to some degree and strengthen the educational effect. Secondly, make innovations in trend effect. The two countries can make full use of their own educational advantages, guarantee knowledge construction through good interactive cooperation and expand some complementary information sources so as to provide a stronger intellectual support for the economic development in northeast China and Russian Far East Area.

To sum up, based on the current complicated Asia-Pacific situation and the inevitable trend of economic globalization, it is extremely necessary to take effective measures to propel the connection between the revitalization of the old industrial base of northeast China and exploitation strategy of Russian Far East Area. In this way, linkage development can be formed in both areas so that both sides can break through their dilemma through win-win cooperation.

\section{Acknowledgement}

Topic name in this paper: Study on Linkage Effect of Revitalization of the Old Industrial Base in Northeast China and Exploitation of Russian Far East Area; topic code: 11BJY067

\section{References}

[1] Wang Yong and Li Lingyan. Analysis on linkage development factors of the old industrial base of northeast China and Russian Far East Area - from the viewpoint of evolutionary economic geography, Journal of Heihe University, 2014, 5 (4):45-46.

[2] Sun Xianmin and Zheng Yajuan. Study on development of Heilongjiang's trade to Russia under new situation, Northern Economy and Trade, 2014 (7):3-4, 7.

[3] Russia] A.B. Ostrovsky and Linlin. Joint development plan of Russian Far East Area and northeast China: issues and prospects, Russian Journal, 2012 (2): 13-23.

[4] $\mathrm{Xu}$ Poling and Jia Chunmei. Innovative path and technological choice for revitalization and change of the old industrial base: economic analysis on new development, Journal of Liaoning University (philosophy and social science), 2013, 41 (4): 34-41.

[5] Zhu Xianping and Mikhail Titarenko. Study on interactive development and energy cooperation between east Russia and northeast China, Changchun: Changchun Publishing House; 2013:9. 